rent changes for $\mathrm{I}^{\circ}$ of temperature being expressed in terms of the horizontal force and vertical force respectively :-

For $x^{\circ} \mathrm{Fahr}$. increase of temperature Apparent decrease of horizontal force

$\begin{array}{ccc}1868 & 1885 & 1886 \\ .00018 & 00026 & 00021 \\ 1882 & 1885 & 1886 \\ .00020 & 00022 & 00020\end{array}$

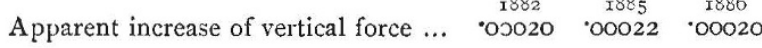

The following are the principal results for magnetic elements for I 885 :-

Approximate mean declination $18^{\circ} 2^{\prime}$ west.

Mean horizontal force... $\quad \ldots\left\{\begin{array}{l}3.9376 \text { (in English units). } \\ 3.8156 \text { (in metric units). }\end{array}\right.$

Mean dip $\quad \ldots \quad \ldots \quad \ldots\left\{\begin{array}{lll}67 & 27 & 28 \text { (by } 9 \text {-inch needles). } \\ 67 & 27 & 32 \text { (by } 6 \text { inch needles). }\end{array}\right.$

$\left\{\begin{array}{lll}67 & 27 & 32 \text { (by } 6 \text { inch needles). } \\ 67 & 28 & 27 \text { (by } 3 \text {-inch needles). }\end{array}\right.$

In the year 1885 there were only three days of great magnetic disturbance, but there were also about twenty days of lesser disturbance for which it may be desirable to publish tracings of the photographic curves. It is proposed to add tracings of the registers on four quiet days to serve as types of the ordinary diurnal movement at four seasons of the year, as was done for I 884 .

The automatic drop of the Greenwich time-ball failed on two days during the past twelve months, on one occasion through accumulation of snow on the mast, and on another through failure in the clock-work apparatus for daily reversal of the currents through the electro-magnets. This apparatus has since been removed, and the direction of the currents is now reversed by hand once a week. On one day the ball was not raised on account of the violence of the wind.

As regards the Deal time-ball, there have been seven cases of failure owing to interruption of the telegraphic connections, and on three days the violence of the wind prevented the raising of the ball. There have been three cases of failure of the I p.m. signal to the Post Office.

No further action has been taken as regards the establishment of hourly time-signals at the Lizard or Start, as the arrangements for preliminary trial of a collapsible cone at Devonport are not yet completed. One of the Transit of Venus clocks (Dent 20Io) has been adapted by Messrs. E. Dent and Co. to give hourly time-signals, and to be synchronised by the help of an auxiliary seconds' pendulum on the plan I proposed in the last report.

The longitude of Gibraltar was determined last year under Capt. Wharton's direction, by exchange of telegraphic signals on August 8, 9, and 12 between Greenwich and Gibraltar, the Eastern Telegraph Co. having courteously given the free use of their telegraph cable for the purpose. The signals were transmitted by relayaction from the ends of the cable to the observing-stations at Greenwich and Gibraltar. Local time was determined at Gibraltar by the officers of H.M.S. Sylvia with the sextant, and at Greenwich by Commander Moore and Lieut. Douglas by means of sextant observations, and also by transits with the transit-circle. In connection with this determination a large number of observations of signals were made at Greenwich for the determination of the personal equations of the different observers in observing telegraph signals. At Greenwich the longitude signals were observed by five observers independently. Commander Moore and Lieut. Douglas made a series of observations at Greenwich last summer for comparison of the relative value of determinations of local time made with a sextant and with a small transit instrument respectively.

The record of the past year shows that the work in all branches tends to increase. This increase could not well be resisted without impairing the efficiency of the Observatory, but year by year it causes more pressure on our limited staff, which, in addition to scientific work, is charged with the ever-increasing duties of a Government Office. In this connection I may mention that a good deal of my own time, as well as that of the Chief Assistant, has lately been occupied with various matters connected with the Navy, reference having been made to me on the subject of gun-directors, mirrors for electric search-lights, and binoculars, in all of which there are involved questions requiring careful consideration.

Commencing with the year 1885, Greenwich civil time, reckoning from midnight to midnight and counting from 0 to 24 hours, has been adopted in the spectroscopic and photographic results as well as in the magnetical and meteorological. It is proposed to defer the introduction of this time-reckoning into the astronomical results till the year I89I, for which year the Board of Visitors have recommended its adoption in the Nautical Almanac. In an Observatory such as this, where observations of various classes are carried on, there is, however, considerable inconvenience in the retention of the present astronomical day, which now involves the use of two systems of reckoning mean solar time in the same establishment.

The construction of an object-glass of 28 inches aperture and of 28 feet focal length, with suitable tube, to be mounted on the south-east equatorial, has been authorised by the Government, and the necessary funds have been provided in the estimates. The work has been intrusted to $\mathrm{Mr}$. Grubb, with whom I have arranged the details of the tube, which is to be of special construction, adapted to the conditions of the mounting, and available for spectroscopy and photography as well as for eye-observations. Mr. Grubb proposes to provide means for readily separating the lenses of the object-glass to such a distance as will give the proper correction for photographic rays. Messrs. Chance are engaged in the manufacture of the glass for the lenses, and have already made a flint disk which promises to be very satisfactory.

In view of the recent development of astronomical photography, I propose to have constructed, for use with the present $12 \frac{3}{4}$-inch refractor of the south-east equatorial, a combination of a convex flint and concave crown lens, which, when placed about 2 feet within the focus, would correct the chromatic aberration of the object-glass for the photographic rays without alteration of the focal length. If this plan succeeds, the instrument would then be well adapted for photography, thanks to the firmness of its mounting and the excellence of its driving-clock.

\section{THE PAST WINTER}

$A T$ the meeting of the Royal Meteorological Society held on May I9 a paper was read on "The Severe Weather of the Past Winter, I $885-86$," by Mr. C. Harding, F.R.Met.Soc. The paper dealt with the six months from October to March in a general way, and with the three months from January to March more in detail, as the latter embraced the period during which the weather was most severe, and in which both frost and snow were exceptionally prevalent. The material used in the discussion was for the most part contributed by the kindness of the Meteorological Council.

The greatest deficiency of temperature throughout the winter occurred in the weeks ending January 25, March I, 8 , and $\mathrm{I}_{5}$, the defect on the average amounting to as much as $9^{\circ}$ and $10^{\circ}$ over the greater part of England. During the fortnight ending March 15 the mean temperature was below the freezing-point in the Midland Counties and in the north-west of England, and, considering the British Islands as a whole, the temperature was lower during this fortnight than in any similar period of the winter. The means for each of the six winter months show that the temperature was below the average over the whole Kingdom in October, January, February, and March. In the east, south, north-west, and south-west of England, and the Channel Islands, as well as over the 
greater part of the Midland Counties, and the north of Ireland, temperature was also below the average in December, whilst in the north-west of England and over a great part of the north of Scotland each of the six months was below the average. There was no part of the British Islands, except the Channel Islands, in which the temperature for each week, from the commencement of January until the third week in March, did not fall to the freezing-point or below, whilst in the south-west of England there was not a single exception after the first week in October, and in the east of Scotland, the north-east and north-west of England, the thermometer fell to $32^{\circ}$ or below in each week from the commencement of November. The lowest shade-temperatures observed in the British Islands were: in January, $-2^{\circ}$ at Braemar on the Igth, and $\mathrm{I}^{\circ} \mathrm{I}$ at Alston on the 20 th ; in February, $2^{\circ} .5$ at Braemar and $7^{\circ} .1$ at Alston on the 5 th ; in March, $-2^{\circ}$ at Alston and $1^{\circ} \cdot 2$ at Buxton on the 7 th, and $2^{\circ}$ at Braemar on the I2th. There were extremely few instances of the temperature falling below $5^{\circ}$; but temperatures below $10^{n}$ were observed in January and March over the greater part of Great Britain.

From the commencement of January to the middle of March there was almost continuous frost, and during this period it froze for upwards of 60 nights at many places in the British Islands. At Great Berkhamsted the minimum temperature registered $32^{\circ}$ or below in January 22 days, February 23 days, March I 8 days, making a total of 63 days between January 3 and March 18 ; whilst on the grass it froze for 73 consecutive nights, from January 5 to March 18. At Cheadle in Staffordshire, Churchstoke in Montgomery, Llandovery in Carmarthen, and Great Berkhamsted in Hertfordshire, it froze for 33 consecutive nights, from February 14 to March 18, whilst at very many stations the frost continued 30 days or more. In Great Britain the longest period of frost occurred between the middle of February and the middle of March, but in Ireland it occurred generally in January. At Greenwich it froze on 28 consecutive days from February 19 to March 18; the observations from 1845 do not show another instance of frost continuing for so long a period without interruption. The only instances of 20 or more consecutive days are :-

24 days in 1858 , from February 17 to March 12 . 22 days in 1879 , from November 20 to December II. $2 \mathrm{I}$ days in 1855 , from January 14 to February 3. 21 days in 1878 , from December 6 to December 26 .

For the three months from January to March there are but few years since 1845 that have a period of continuous frost of one-half the length of that in 1886 . The years with fifteen days or more are respectively :-

I 886 (28), I 858 (24), I 855 (21), I 86I (I9), I 88I (I6).

Taking the actual days with frost at Greenwich, irrespective of continuity, there was frost on 53 days in the present year (1886) from January to March. In I 855 the number of frosts in the corresponding period was 58 , but the only other instance of more than 50 days was in 1858 , when the number was 53 .

Probably the most interesting feature in connection with the past winter was the excessively cold weather experienced over the whole country at the commencement of March. The Greenwich observations from I8I4 only show two instances of a similarly low temperature-these were in 1814 and 1845 . The unusual frequency with which snow fell was also a matter of interest, and the heavy drifts occasioned serious blocks on many of the northern railways.

The records of the London Skating Club show that there was skating on the Club water in Regent's Park on 38 days during the winter, and I885-86 was the only winter in which there was skating in each of the four months from December to March since the formation of the Club in 1830 , and the only March records of skating in the 56 years are 16 days in 1886,12 days in 1844,10 days in 1858 , and $\mathrm{I}$ day in $\mathrm{I} 8533^{\circ}$ On a pond at Pinner there was almost continuous skating for 3 months, and and at Rickmansworth for about 70 days, but at both places the ice was most carefully nursed. On January 7 there was safe skating on snow-ice after one night's frost.

The temperature of the water in the Thames at Deptford was, on the mean, slightly in excess of the air. From January 8 to March 20 the entire range was from $40^{\circ}$ to $34^{\circ}$; and from March 1 to 19 the maximum temperature was $36^{\circ} \cdot 5$ and the minimum $35^{\circ}$, showing a total range of $I^{\circ} \cdot 5$.

The recent temperatures observed at several stations over England show that at $\mathrm{I}$ foot below the surface the greatest cold for the winter was reached during the first 17 days of March. The mean was generally about $2^{\circ}$ in excess of the mean air temperature. In January the earth temperature at 1 foot was from $2^{\circ}$ to $3^{\circ}$ below the average over the whole country, whilst in February it was from $4^{\circ} .5$ to $6^{\circ} .5$ below the average ; the first 17 days of March, however, show a much larger defect on the average, the deficiency ranging from 6.3 at Lowestoft to $8^{\mathrm{c}} .5$ at Norwood. The temperature of the soil at 2 feet was generally about $2^{\circ}$ in excess of that at I foot.

The logs of ships traversing the North Atlantic show that the abnormal conditions which prevailed over the British Islands and indeed over nearly the whole of Europe extended also a considerable distance to the westward. They show a decided tendency to a low barometer, during the early months of 1886 , in the locality where a high barometer generally prevails, and to the north of this low barometer strong and persistent easterly winds were experienced. These facts tend to show a general reversal of conditions over the Atlantic which would doubtless be very intimately related to our own exceptional weather.

\section{THE ASTRONOMICAL DAY}

$T H E$ recently published report of the Science and $A r \hat{\imath}$ Department contains some most important information showing what the recent Government action has been in relation to the resolutions passed at the Washington Conference.

The first letter that we need refer to is one from the Astronomer-Royal, in April last year, suggesting that reference should be made to various scientific Societies, in order to obtain an authoritative expression of opinion from the scientific men in this country interested in the question. This was followed by a meeting of the committee appointed to advise the Science and Art Department on the matter. The following resolution was adopted by the committee, which consisted of Prof. Adams, the Astronomer-Royal, General Strachey, Captain Sir Frederick Evans (since deceased), Captain Wharton (the Hydrographer), and Colonel Donnelly :- "The committee recommend that the report of the British Dele. gates to the Washington International Prime Meridian Conference, with the resolutions adopted by that body, be communicated to certain Departments of State, learned Societies, telegraph companies, \&c., and that they be informed that the resolutions appear to be such as commend themselves for adoption; but before informing the American Government to that effect they would be glad to receive their opinions on the subject."

The Science and Art Department then addressed a letter to various public offices, scientific bodies, and telegraph companies. Their replies may be thus con densed.

The Eastern Telegraph Company, and the Eastern Extension, Australian, and China Company, state that they have always adopted the twenty-four-hour system in timing their messages, thus avoiding the necessity of signalling the letters a.m. and p.m. 